\title{
New Technologies in Construction Materials Based on Environmental Approach (Case Study: Double Skin Facades)
}

\section{Esmaeil Zarghami}

Associate Professor, Shahid Rajaie Teacher Training University, Tehran, Iran Email: ezarghami@sittu.edu

\author{
Ali Sadeghi Habib Abad \\ *Master of Architecture, Shahid Rajaee Teacher Training University, Tehran, Iran \\ *Corresponding Author. Email: a.sadeghi@srttu.edu
}

Doi:10.5901/mjss.2015.v6n6s6p17

\begin{abstract}
Energy crisis and daily increase in environmental pollution due to production of greenhouse gases, especially in construction industry is among important topics of the recent century architecture. Utilizing proper materials as one important factor in this industry, has been the concern of many researchers. Hence the following research has the aim of investigating heating performance of new kinds of materials in architecture industry and also replacing double skin facades to maintain thermal comfort of the residents, with minimum energy consumption. Sustainable architecture is one of the most important elements of sustainable development topic, because more than half of greenhouse gases in the world are produced by residential homes. Considering that the amount of greenhouse gases produced in developing countries is more than that of developed countries, hence it becomes clear the necessity of considering environmental approach in the field of architecture works. In this research while doing desk studies and investigating achieved research, the descriptive - analytical method and also field method have been applied and through thermal performance analysis of building materials and using energy simulation software (IES - VE) and their comparison, the appropriate pattern is proposed.
\end{abstract}

Keywords: new technologies, environmental, double skin façade, sustainable architecture

\section{Introduction}

Man from the beginning of creation, has been after utilizing resources for his benefit and welfare. That kind of welfare which has been accompanied by imbalance in the nature, Introducing various pollutants in environment and damaging its figure. With agricultural revolution and following it the industrial revolution in the years $1700-1850$, an era began characterized by unlimited use of natural resources by man together with not respecting environmental potency and various kinds of pollutions associated with it (J. Long, 2004) After industrial era and stepping in to the technology era, damages done to the nature and problems arising from this damage became the focus of environmental oriented people, so far that experts, by establishing a relationship between development and environment, introduced the topic of sustainable development with the aim of utilizing natural resources restricted by environment's potency and the necessity of remaining useful for the coming generations. In continuation, this approach resulted in emergence of a new concept called Ecotechnology in the 1970s (Gorji Mahlebani, 2010). Double skin facades which have become rapidly widespread in Europe in recent two decades, provide natural ventilation while controlling noise, wind and rainfall. These facades will have broader usage in contemporary architecture. Double skin facades which perhaps are imitations of the traditional architecture are cases with glass walls that are revived in contemporary architecture. Being double skin makes it possible to regulate the heat, cold, light, wind and also the outside noise, So that it provides comfort and welfare of the residents without energy loss. The epithet "double skin facade" in reality is the same idea of flexible facade with intelligent control. The building skin has been traditionally considered as a barrier between the interior space and the exterior variable weather conditions in a building and its performance has been evaluated in terms of its ability to segregate interior and exterior spaces of a building, While modern design ideas, look at the skin of a building in terms of a barrier which makes the balance between the interior space and exterior environment of a building (McClintock, 1997). In a research Hensen et al. Show that simulation of double skin facade includes investigation of such factors like temperature, and air flow fluctuations ,so that through proper analysis of these factors and providing appropriate solutions, considering special 
conditions of the project, one could reduce heating and cooling loads of a building (Hensen,2002). One application of the building façade is to protect the building against weather conditions and prevention of exchange of energy from inside to outside and vice versa. To achieve this goal, various solutions have been proposed like using interior and exterior sun shades, advanced technologies, glass facades, active and inactive air conditioning systems and double skin facades; each helping us reaching out this goal (Hamza,2008).

\section{Research Methodology}

At the first stage of desk survey, domestic and foreign books and articles, also texts and interviews available in the literature and magazines were consulted. At the end of this stage, acquaintance with primary fundamentals and also knowledge and investigation of building materials and their features began. Following that, the field research stage was initiated. At this stage based on the first stage studies, a questionnaire was prepared about conventional building materials available in the construction and housing market. Then this questionnaire, was completed by experienced and knowledgeable experts, and the results of the field studies were investigated and work continued by comparing each material in terms of its heating performance. Using the results, those materials used as exterior walls were classified in four categories and the most conventional materials used by the architects and purchasers are shown as follows:

Table 1 - Results of the questionnaire and classification of the conventional materials

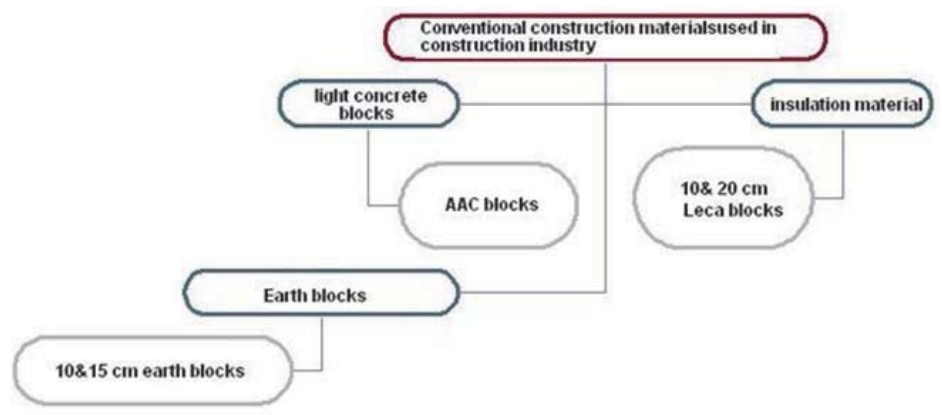

\section{Research Hypothesis}

Investigating and knowing the influencing factors on environmental architecture yielded the following hypothesis:

"Utilizing proper materials in buildings and adopting an appropriate and intelligent method, the desired and optimized options of these materials could be identified in the buildings, to be in line with sustainable development. Also the pattern of double skin facade, having its own performance, leads the building architecture towards a sustainable architecture."

\section{Necessity and Importance of the Research}

During recent two decades, the environment and its political, economical and social dimensions gradually have crossed the interior borders of the countries and as an international problem is being accepted as a universal requirements by all countries. What is important is the murmur of World Free Trade and the issue of joining world trade organization by countries of the world and this would sooner or later encompass our country's economy. Considering the world's rapid growth of population and reaching its number to over 7 billion people, energy consumption has greatly increased, so that it is claimed that energy consumption during the 1970-2000 period was equal to energy consumption from the human genesis up to the year 1970. Also with respect to the intensity of energy consumption and unprecedented environmental pollutions especially increase in the amount of greenhouse gases in recent years and warnings of the scholars, the issue of sustainable development has been introduced since 1980s. One of the most important issues of sustainable development is the topic of sustainable architecture. Because more than half of greenhouse gases in the world are produced by the residential homes and as this rate is higher in the developing countries rather than the developed countries, the issue of sustainable architecture becomes more important. 


\section{Sustainability}

The source of "sustainability": the word 'sustainability' in its current meaning is defined as "what that could be endured in future", in fact sustainability is maintained when a set including social sustainability, economical sustainability and environmental sustainability is provided.

Principles of sustainability:

1- Using nature-based solutions.

2- Compatibility with the environment rather than changing it.

3- Symbiosis of made environment and the natural environment and.

4- Unity of the whole and autonomy of the components

5- Reservation of un-renewable energy

6- Recycling of buildings and construction materials

7- Respecting the project base

8- Simultaneous employment of above mentioned principles.

Three fundamental principles of sustainability:

First principle: Saving in resource consumption

Second principle: Design based on life- cycle

Third principle: human resource planning

Sustainable architecture

Perhaps it suffices to cling to a simple and process - based definition "sustainable development is that kind of development which improves human health and ecological systems in the long - term. "Sustainable development is a development that meets the needs of the present while respecting the future generation ability in maintaining his own needs". Along with observing objectives of sustainable development "environmental sustainability" in relation to architecture finds extreme importance and environmental issues which have endangered the human kind future, have obliged the architects to find solutions.

The concept of sustainability in the 1970s was the result of natural growth of new logical awareness toward global environmental problems and development issues which in turn were influenced by factors such as 1960s environmental movements and published books like 'The limits to growth' and the first UN conference on environment and development which was held in 1972 in Stockholm. Buildings and houses in themselves consume 1/6 of global water resources, 1/4 of wood produced and $2 / 5$ of fossil fuel and produced materials in the world, In addition buildings are responsible for half of greenhouse gases in the world, According to the available statistics, construction rates would double during the next 20 40 years, The term "sustainable development" in early 1970s were used in relation to environment and development. Sustainable development is a process to maintain sustainability in every activity which needs resources and rapid and integrated replacement of them. Sustainable development along with economic growth and human development in a community or a developed economy, attempts to gain continued development beyond economic development. Alan Fricker recognizes sustainability as a kind of future envisioning, in fact it is a road map which is concentrated upon collection of ethical and spiritual values and principles and that which controls human behavior (Munier,2005).

How should we design our homes and select the material are among the main problems which would impact the future construction of our homes. Environmental architecture has gained significant successes during the last few years. These include issuing of new structural techniques and sale of appropriate materials consistent with environmental architecture notions. Generally environmental architecture is based upon 4 major principles:

1- Protect water, wind and other natural resources.

2- Maintain the health of our environment.

3- Maintain the economic growth of our country .

4- Provide a high quality life for the citizens.

These principles are subsets of 3 structural and influential factors in sustainable architecture : 1- geography 2culture 3- vernacular architecture.

Generally the green process is so depicted that all topics are interrelated and in every decision making process all its aspects should be surveyed and thus the idea of investigation of principles in a separate manner will be against it. As a whole, there are various principles present in construction of every structure which possesses common issues to be discussed, nevertheless topics presented here a collection of different principles that considering them would provide balance and emergence of environmental architecture. 


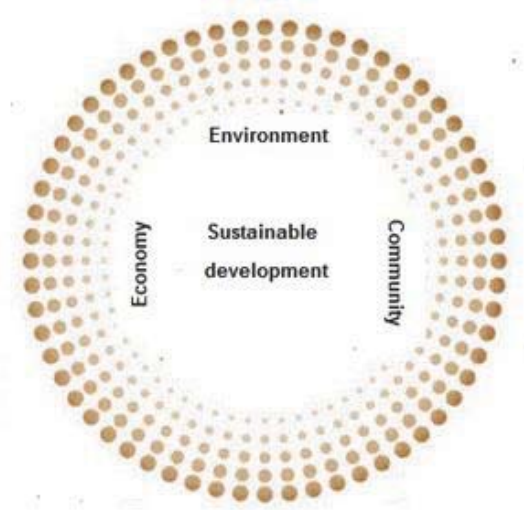

Figure 1 - Three main elements of sustainable development

From the view point of Richard Rogers, the sustainable architecture aims to confront future needs without damaging natural resources remained for the next generation. With respect to buildings, sustainable design refers to the efficiency of resources , minimum energy, flexibility and the long life (Rogers, 2007).

Principles that should be observed that a building could be accounted among the sustainable buildings are as follows (Ghiasvand, 2007):

1- Energy preservation, 2- Coordination with climate, 3- Reduced use of new resources, 4- Residents needs , 5Coordination with the site, 6 -Holism

\section{Material Introduction and Heating Performance}

Heat in a building is transferred by conduction, convection and radiation, which in calculations of heating load in winter season the effect of radiation is ignored. Therefore heat losses in buildings include: heat loss through the walls, roofs, windows floor and air penetrated through the building (Tabatabaei, 2001).In Table 2-4-5, the heating performance of the materials by IES software are presented.

Table 2 - Details of conventional construction materials

\begin{tabular}{|l|c|c|c|c|c|}
\hline Wall type & $\begin{array}{c}\text { Dry unit } \\
\text { weight }\left(\frac{\boldsymbol{k g}}{\boldsymbol{m}^{\mathbf{3}}}\right)\end{array}$ & $\begin{array}{c}\text { Thickness } \\
(\mathbf{c m})\end{array}$ & $\begin{array}{c}\text { Effective thermal conduction } \\
\text { coefficient }(\mathbf{w} / \mathbf{m} \cdot \mathbf{k})\end{array}$ & $\begin{array}{c}\text { Thermal resistance } \\
\left(\boldsymbol{m}^{\mathbf{2}} \cdot \boldsymbol{k} / \boldsymbol{w}\right)\end{array}$ & $\begin{array}{c}\text { Surface heat transfer } \\
\text { coefficient }\left(\mathbf{w} / \boldsymbol{m}^{2} \cdot \boldsymbol{k}\right)\end{array}$ \\
\hline Earth block & $2100-2200$ & 15 & 0.92 & 0.16 & 1.81 \\
\hline Heblex & 700 & 15 & 0.17 & 0.88 & 0.95 \\
\hline Silex & $600-700$ & 15 & 0.17 & 0.88 & 0.95 \\
\hline CLC & 450 & 15 & 0.22 & 0.68 & 1.17 \\
\hline Perlite & $400-600$ & 15 & 0.24 & 0.62 & 1.26 \\
\hline Leca & 900 & 15 & 0.20 & 0.75 & 1.08 \\
\hline 3d panel & - & 13 & 0.08 & 1.62 & 0.55 \\
\hline LSF & - & 13 & 0.07 & 1.85 & 0.50 \\
\hline
\end{tabular}


Table 3 - Details of conventional construction materials

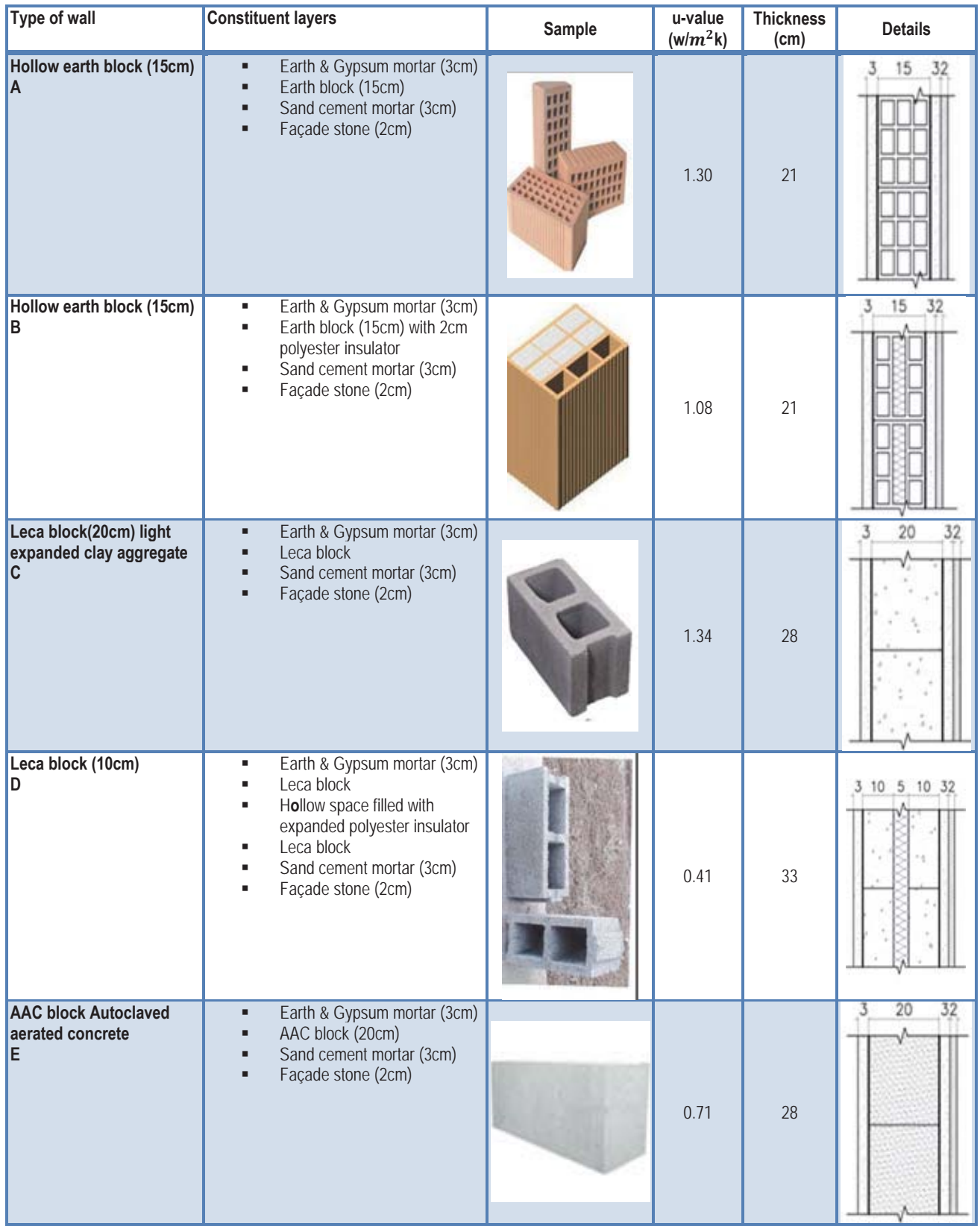

Table 4 - Thermal characteristics of materials

\begin{tabular}{|c|c|c|c|l|}
\hline Diffusivity a= $\lambda / \mathrm{pc}$ & $\mathrm{P} \mathrm{kg} / \mathbf{m}^{3}$ & $\lambda$ w/mk & $\boldsymbol{C}_{\boldsymbol{p}} \mathbf{j} / \mathbf{k g k}$ & \\
\hline $7.00 \mathrm{E}-07$ & 1700 & 1 & 840 & Brick \\
\hline $4.60 \mathrm{E}-07$ & 1300 & 0.5 & 840 & Earth block \\
\hline
\end{tabular}




\begin{tabular}{|c|c|c|c|l|}
\hline $\mathbf{2 . 5 6 E - 0 7}$ & 900 & 0.23 & 1000 & Leca \\
\hline $\mathbf{2 . 4 3 E}-07$ & 700 & 0.17 & 1000 & AAC (Autoclaved aerated concrete) \\
\hline 1.99E-06 & 15 & 0.04 & 1340 & Expanded polyester \\
\hline
\end{tabular}

Table 5: Thermal dynamic characteristics of walls

\begin{tabular}{|l|c|c|c|c|c|c|c|c|}
\hline & $\begin{array}{l}\text { u-value } \\
\mathbf{w}^{\prime} \mathbf{m}^{\mathbf{2}} \mathbf{k}\end{array}$ & $\mathbf{C m ~ K J / \mathbf { m } ^ { 2 } \mathbf { k }}$ & Admittance $\mathbf{w} \mathbf{m}^{\mathbf{2}} \mathbf{k}$ & Decrement factor DF & Delay time (Hrs) & Surface factor $\mathbf{F}$ & Thickness (m) & $\boldsymbol{\lambda}$ eq block \\
\hline A & 1.30 & 71.46 & 3.52 & 0.811 & 4 & 0.717 & 0.21 & 0.28 \\
\hline B & 1.08 & 71.73 & 3.63 & 0.802 & 4 & 0.729 & 0.21 & 0.22 \\
\hline C & 1.34 & 72.46 & 3.57 & 0.812 & 4 & 0.709 & 0.26 & 0.39 \\
\hline D & 0.41 & 72.46 & 4.01 & 0.439 & 9 & 0.695 & 0.31 & 0.21 \\
\hline E & 0.71 & 94.46 & 3.77 & 0.385 & 10 & 0.686 & 0.26 & 0.17 \\
\hline
\end{tabular}

\section{Solution for Reducing Heat Loss}

One way to reduce heat loss is the use of insulators. Insulators are divided into two categories: bulk insulators and reflective insulators. bulk insulator acts as a weak thermal conductor, glass wool, mineral wool, cellulose fibers and foam boards (polyurethane) belong to this category which have applications in construction industry. Reflective insulators need an air space so that by reflecting major part of radiation or preventing heat transfer by radiation in the walls of this air space, thus they reduce heat movement through the walls. This kind of insulators have an effective role in limiting heat received in the summer (heat acquired by the Sun) and do not affect heat losses in winter (where major losses are due to conduction and convection). Still air is a very suitable insulator ,so insulators either have small pockets of air like foam boards or absorb air on to their surface like fiber insulators. For this reason insulators have very small conduction coefficient . Glass wool and mineral wool insulators form large surfaces in contact with the air and thus air molecules are absorbed onto these surfaces and produce layers of still air. However these insulators prevent heat transfer by convection within themselves (Brand, 1993).

\section{Double Skin Façade}

Double skin facades having at least two skins between living space and exterior environment are differentiated from other kinds of facades. In the cavity between these two skins there is a path for the air flow that makes is different with a double glass window. The ventilation of this intermediate space could be natural or mechanical. Glass skins could be one or doubled skins. Often for the sake of protection and prevention of head loss in the cold season, shading devices are implemented at the entry of the cavity. In other words double skin facades are a form of building skin consisting two layers (interior and exterior facade) with various glass materials that are separated by a cavity having ventilation capabilities (Fig.2) (Azarbayjani,2010).
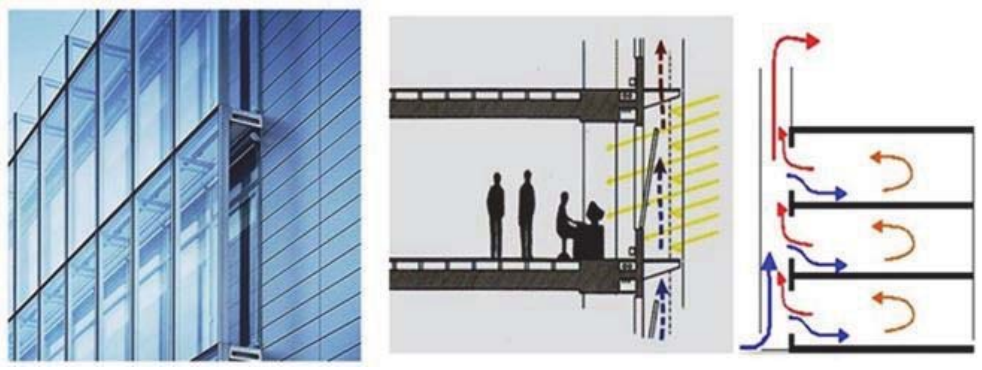

Figure 2 - Double skin facades

Double skin facade is an architectural idea consisting of two different skins which are separated by an intermediate air cavity. This cavity has the function of enclosing solar radiation and producing greenhouse effect in the winter and evacuation of the hot air within cavity in the summer. Therefore while reducing cooling and heating loads, it provides 
thermal comfort and quality of the interior air (Hashemi, 2010). This technology was initiated in cold climates then it was developed dramatically in Europe, North America and Japan after the year 1980 (Hamza, 2008). Recently, with rapid economic development, new buildings with double skin facades in very hot climates in the summer and cold winters are being used(Zhou,2010). In recent two decades, relatively wide spread research have been conducted on the performance of double skin facades. In the year 2001, Gan (G.Gan,2001) in a pioneering research work on double skin facades, numerically evaluated the rate of heat transfer through these facades and in various conditions. Hensen et al. in the year 2002 during a research developed fundamentals of 2-dimensional modeling of double skin facade (Hensen,2002). Also in the same year Kragh introduced the idea of mechanical ventilation of double skin facades and investigated their efficiency( Kragh,2002). In the year 2010 Huckemann et al. in an experimental research studied the effect of double skin facades on thermal comfort of the residents and the interior air quality and compared the results with one skin facades (Huckemann, 2010). In Iran Hashemi et al. investigated the behavior of double skin ventilated facades for Tehran climate both experimentally and numerically (Hashemi, 2010). Their results showed that in the hot season of the year, the temperature of flowing air through double skin facades is about 1-10 Celsius degrees higher than outside temperature, this could increase the summer load. They also demonstrated that using sun shades for southern double skin facade, significantly enhances performance of these facades.

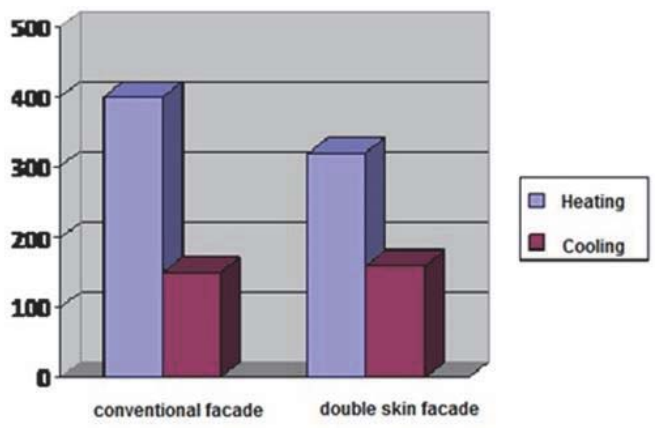

Figure 3 - Diagram comparing annual rate of energy consumption in a building
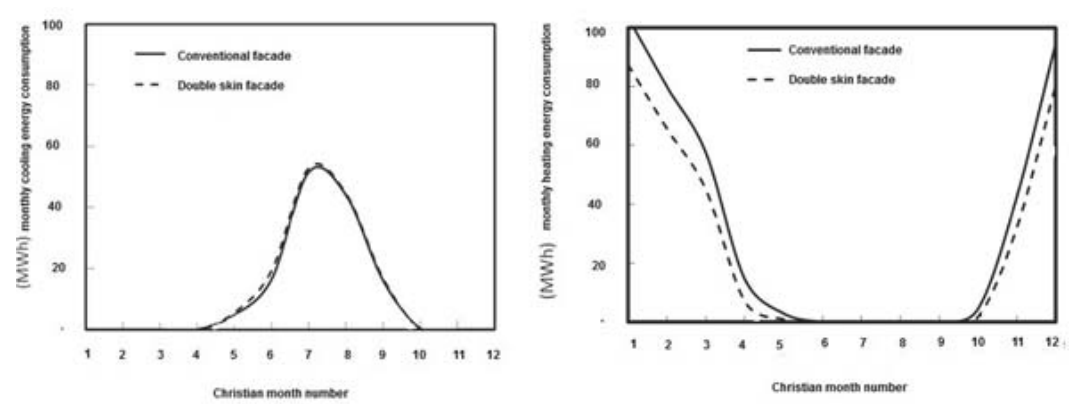

Figure 4 - Diagram comparing heating and cooling energy consumption using double skin façade

\section{Discussion and Conclusion}

Considering the daily progress of country after Islamic Revolution of Iran and introducing Iran as one of the major countries rich in renewable energy resources in the world, the construction industry requires a new standpoint because Iran's new conditions do not recognize the traditional design viewpoint and conventional mass construction methods adequate for preservation of environment. So with respect to limited non-renewable energy resources and the awareness among knowledgeable people concerning advantages of the new and pure energies, preservation of the environment and prevention damage to nature by introduction of artificial pollutants also priority of developing a sustainable design inspired by the state of the art styles in the world, the need for this kind of design is more felt. Among investigations 
achieved the double skin facade system is recognized to be the most appropriate one, followed by autoclaved aerated concrete (AAC) blocks, and leca blocks for exterior wall system, respectively. It should be noted that relying solely on data and results obtained is not logical because these information are obtained through interviews and quality analyses. At the end it should be declared that the architect has the task of designing building $s$ and for the sustainable approach to have appearance in every corner of the building there is need for a suitable drawing. The one that in addition to observing aesthetics points involve maximum use of available energy at the site. Furthermore in design make use of those facilities that have least rates of leakage and energy loss. Another design criterion consistent with the nature, is a design inspired by nature, a structure that in a glance reminds one of nature's elements, could in itself be accounted a kind of culture building.

\section{References}

R. Brand, 2003, "Architectural details for insulated buildings", 2nd edition, translated by Dr. Hossein Mozaffari, Tehran University Publication.

G. Long Catherine (2007). Agricultural Revolution (translator: Mehdi Haghigat-Khah) Tehran, Goognoos (2004).

Djavad Ghiasvand,1385, "Interaction between architecture and new sustainable energies" Road and Construction Journal, №. 38

Gorji Mehlabani, Yousef (2010) Sustainable architecture and its criticism in the realm of environment. Scientific - Research Journal of "Iranian scientific association of architecture".1(1), pg. 91-100

M. Tabatabaei,2001, "Calculations of Building Facilities", 7th edition, Karun Press, Tehran

Azarbayjani, m. (2010). Beyond Arrows: Energy Performance Of A New, Naturally Ventilated Double-Skin Facade Configuration For A High-Rise Office Building In Chicago (Doctoral dissertation).

G. Gan,(2001), Thermal transmittance of multiple glazing: computational fluid Dynamics prediction, Applied Thermal Engineering, Vol. 21 , No. 15, pp. 1583-1592.

Hamza, N. (2008). Double versus single skin facades in hot arid areas. Energy and buildings, 240-248.

Hamza, N. 2008. "Double versus single skin facades in hot ardi areas". Energy and buildings. 40. Pp 240-248.

Hashemi, N., Fayaz, R., \& Sarshar, S. (2010). Thermal behaviour of a ventilated double skin facade in hot arid climate. Energy and Buildings, 42(10), 1823-1832.

Hensen, J., Bartak, M., \& Drkal, F. 2002. Modeling and Simulation of a Double-Skin Façade System. ASHRAE Transactions .p 108.

J. L. M. Hensen, M. Bartak, D. Frantisek,(2002), Modeling and simulation of double-skin façade system, ASHRAE Transactions, Vol. 108, No. 2, pp. 1251-1259.

M. Kragh,(2002), Mechanically ventilated double skin façades in: M. Anson, J. M. Ko, E. S. S. Lam, Advances in Building Technology Eds., pp. 1233-1240, Oxford: Elsevier.

McClintock, M., \& Perry, J. 1997. "The Challenge of 'Green' Buildings in Asia". In: International Conference of Building Envelope Systems and Technologies (ICBEST). Bath University, UK.

Munier, Nolberto (2005), Introduction to Sustainability: Road to a Better Future, The Netherlands: Springer.

N. Hashemi, R. Fayaz, M. Sarshar, (2010), Thermal behavior of ventilated Double skin facade in hot arid climate, Energy and Buildings, Vol. 42, No. 10pp. 1823-1832.

Rogers, Richard (2007), Sustainability, www.richardrogers.co.uk.

V. Huckemann, E. Kuchen, M. Leão, É. F. T. B. Leão, (2010), Empirical thermal Comfort evaluation of single and double skin façades, Building and Environment, Vol. 45, No. 4, pp. 976-982.

Zhou, J., \& Chen, C. (2010). A review on applying ventilated double-skin facade to buildings in hot-summer. Renewable and Sustainable Energy Reviews, 14(4), 1321-1328. 